\title{
CONTRIBUIÇÕES DO PROGRAMA NACIONAL DE CRÉDITO FUNDIÁRIO PARA AS COMUNIDADES RURAIS EM PORTALEGRE/RN
}

\author{
Maria Aparecida Gomes de Paiva* \\ Boanerges de Freitas Barreto Filho**
}

Resumo: Tendo como propósito reduzir os problemas decorrentes da concentração de terras, renda e da pobreza no meio rural foi criado o Programa Nacional de Crédito Fundiário (PNCF). O presente artigo descreve a situação socioeconômica dos agricultores familiares beneficiados com financiamentos para a aquisição de terras em Portalegre/RN do Programa Nacional de Crédito Fundiário (PNCF). Para tanto, foi realizada pesquisa de campo, aplicação de questionários e entrevistas com os beneficiários residentes em cinco assentamentos, coleta de dados nas associações, registro fotográfico e pesquisa bibliográfica. Observou-se que o acesso ao crédito fundiário permitiu a aquisição de terra para os assentados, sendo indispensável para tal conquista, contudo o acesso à terra não foi suficiente para consolidação das atividades produtivas realizadas nas áreas dos assentamentos. Ressaltem-se a necessidade de aprimoramento das técnicas produtivas, ampliação da cooperação entre os assentados, maior engajamento das associações, oferecer assistência técnica e integrar as ações do Poder Público.

Palavras-chave: Programa Nacional de Crédito Fundiário. Agricultura familiar. Assentamentos.

Abstract: With the purpose to reduce the problems arising from the concentration of land, income and poverty in rural areas was created the National Land Credit Program. This article describes the socio-economic situation of the farmers benefit from funding for land acquisition in Portalegre/ RN National Land Credit Program. To this end, field research, questionnaires and interviews with beneficiaries resident in five settlements, collection of data in the bindings, photographic record and bibliographical research. It was noted that access to land credit allowed for the acquisition of land for the settlers, being essential for such achievement, however access to land was not enough for consolidating productive activities carried out in the areas of settlements. Underscore the need for improvement of production techniques, expansion of cooperation between the settlers, greater involvement of associations, provide technical assistance and integrate the actions of the public authorities.

Keywords: National Land Credit Program. Family farming. Settlements.

\footnotetext{
* Bacharela em Economia pela Universidade do Estado do Rio Grande do Norte (UERN). Endereço para contato: BR 405, KM 3, Arizona 59900-000 - Pau dos Ferros/RN. E-mail: aparecidagpa@hotmail.com

** Professor Departamento de Economia. Curso de Mestrado Acadêmico em Planejamento e Dinâmicas Territoriais (CMPDT). Universidade do Estado do Rio Grande do Norte (UERN). Endereço para contato: BR 405, KM 3, Arizona 59900-000 - Pau dos Ferros/RN. E-mail: boanerges.sms@hotmail.com
} 


\section{Introdução}

O Estado brasileiro implantou, a partir de meados da década de 1990 até 2012, programas com vistas à promoção do Desenvolvimento Rural (DR), inclusive com ações direcionadas para a Reforma Agrária. Merecem destaques os programas a cargo do Ministério de Desenvolvimento Agrário (MDA), extinto pelo atual governo, dentre os quais, pode-se apontar o Programa Nacional de Fortalecimento da Agricultura Familiar (PRONAF), o Programa de Aquisição de Alimentos (PAA) e o Programa Nacional de Crédito Fundiário (PNCF). Tais programas podem assumir características diferenciadas de acordo com o perfil do agricultor, da região ou da atividade produtiva que o produtor desenvolve.

Para fins de delimitação, este trabalho foca as contribuições do Programa Nacional de Crédito Fundiário (PNFC) em cinco ações de assentamentos em Portalegre/RN.

O PNFC foi criado no ano de 2003 em substituição ao Programa Banco da Terra. Para Galindo (2015), o objetivo central do Programa é contribuir para a redução da pobreza rural e para a melhoria da qualidade de vida das famílias beneficiadas, pois, com a aquisição das terras poderiam produzir tanto para o autoconsumo quanto para o mercado, aumentando efetivamente a renda familiar (GALINDO, 2015).

De acordo com Santos e Silva Neto (2011), as políticas de acesso à terra e ao crédito não foram construídas como um ato de boa vontade do Estado brasileiro. Elas são conquistas gestadas no seio dos movimentos sociais de trabalhadores do campo, ou seja, foi a organização dos trabalhadores que forçou o Estado a agir. Neste sentido, a criação do Programa representou importante conquista para o Movimento Sindical dos Trabalhadores Rurais, pois foi instituído um instrumento de financiamento para aquisição de terras e implantação de melhorias, facilitando a permanência no campo das famílias que são beneficiadas, consequentemente, diminuindo o êxodo rural (SANTOS, SILVA NETO, 2011).

Diante do exposto, o artigo descreve a situação socioeconômica dos agricultores familiares contemplados com financiamentos para a aquisição de terras em Portalegre/RN, com assentamentos localizados nas comunidades rurais: Bom Jardim, Estrondo, São Francisco e Serrinha e denominados pelo agricultores familiares como assentamentos Catolé, São Francisco, São Miguel, Serrinha e Terra Boa.

Para tanto, foi realizada uma pesquisa de campo nas cinco áreas de assentamento, coleta de dados nas associações, registro fotográfico e pesquisa bibliográfica. 
Durante a pesquisa de campo foram realizadas entrevistas semiestruturadas e aplicação de questionários com os assentados contemplados pelo PNCF em Portalegre/ $\mathrm{RN}$, além da observação direta (fotografias para a caracterização dos assentamentos). Também foram coletadas informações em sites oficiais, nas associações criadas para fins de captação dos recursos e pesquisa bibliográfica em autores renomados, como Schneider, Mattei e Cazella (2004), Santos e Silva Neto (2011), Martine (1991), Rodrigues et al (2017), Galindo et al (2015).

\section{Questão Agrária e o PNCF}

Ao longo da história, as atividades agropecuárias estiveram em constante processo de inovação para alcançar maior produtividade. De acordo com Martine (1991), a modernização da agricultura no Brasil começa a ganhar corpo a partir da década de 1950, passando na década seguinte (1960) pela implantação do setor industrial voltado para a produção de insumos e equipamentos para a agricultura.

Ressalte-se que a prioridade foi modernizar a grande propriedade, considerada como unidade capaz de incorporar o pacote da revolução verde (insumos agroquímicos e equipamentos modernos), articulando-se tal movimento com a estratégia de industrialização do país perseguida pelo Estado. A caificação (crescimento dos Complexos Agroindustriais - CAI’s) do setor já era bem visível na década de 1980 e o debate sobre a Reforma Agrária era considerado ideológico, arcaico e superado pela modernidade (MARTINE, 1991).

Tendo priorizado a solução da problemática agrícola, em detrimento da questão agrária, tem-se que a estratégia de modernização atendeu as expectativas de ampliação da produção agropecuária, inclusive para geração de excedentes para exportação e a consequente geração de divisas para o país. Também serviu para reduzir o peso dos alimentos na cesta de consumo dos trabalhadores, liberando parte da renda para consumo de produtos industrializados. No aspecto social, pode-se afirmar que a modernização da agricultura negligenciou, quase que totalmente, a pequena produção e, mais ainda, os aspectos relacionados a importância de redistribuir terras (MARTINE, 1991).

A distribuição de terra se constituiu, ao longo da história nacional, como um verdadeiro tabu, e, mesmo contando com um vasto território mantido apenas para fins de controle da terra, os diversos governos não se esforçaram para solucionar a questão agrária. 
Verdadeiramente, o Estado foi importante agente para assegurar os interesses dos latifundiários e preservar o status quo da classe dos proprietários. Saliente-se o modelo estruturado pelo colonizador português através das Capitanias Hereditárias, em seguida a distribuição de Sesmarias, a Lei de Terras da época imperial que proibiu a ocupação das terras devolutas, além de medidas em favor das oligarquias rurais, usineiros e as prioridades e facilidades para obtenção de crédito pelos grandes proprietários (INCRA, 2011).

O quadro desfavorável não impediu a luta de inúmeros movimentos sociais pela conquista da terra. Destacam-se as inúmeras revoltas e ações orquestradas (Canudos, Ligas Campesinas, Movimento de Trabalhadores Sem Terra, ações da CONTAG etc.) ao longo do tempo para a obtenção de respaldo estatal para o enfrentamento da questão agrária. Embora a repressão tenha sido a resposta mais evidente (vide o massacre em Canudos), tens que, a partir da década de 1950, os diversos governos passaram a considerar a questão agrária, ainda que de forma muito incipiente.

Evidencie-se que ações concretas foram pontuais e a implantação sistemática de um amplo Programa de Reforma Agrária ainda não se concretizou. Ademais, a política de assentamentos realizada pelo Estado brasileiro não conseguiu assegurar condições adequadas para que os agricultores e suas famílias alcancem um padrão satisfatório de produção e produtividade.

Reconhecendo-se as dificuldades ainda remanescentes para à aquisição de terra com vista a realização de uma reforma agrária, bem como das insuficientes ações para a consolidação produtiva de agricultores familiares descapitalizados, foi implementado o Programa Nacional de Crédito Fundiário (PNCF), sucedâneo do Banco da Terra (1998).

De acordo com Rodrigues et al (2017), o PNCF foi instituído no governo Lula (2003-2006), a partir da junção do Programa de Crédito Fundiário - Combate à Pobreza Rural (PCF-CPR) e do Banco da Terra.

As diretrizes do Programa indicam que a partir do acesso à terra, também devem ser contempladas ações para a mitigação da pobreza rural e melhoria da vida dos agricultores familiares. Objetivando-se garantir a produção para autoconsumo e comercialização de excedentes, promovendo-se a consolidação da produção agrícola familiar e, consequentemente, a redução do êxodo rural (RODRIGUES et al, 2017).

De acordo com as diretrizes do Programa Nacional de Crédito Fundiário (2006), o financiamento se destina à aquisição de imóvel rural, assegurando-se recursos para a estruturação da unidade produtiva (investimentos iniciais na produção, assistência técnica, infraestrutura produtiva), para a implantação de infraestrutura 
básica (casa, rede de estabelecimento d'água, estradas internas à propriedade, energia elétrica, etc.) e projetos comunitários de convivência com a seca no Semiárido e de recuperação ambiental. Distribuindo-se em três linhas: Combate à Pobreza Rural (CPR), Nossa Primeira Terra (NPT) e Consolidação da Agricultura Familiar (CAF) (MDA, 2006).

Ressalte-se que os contemplados pelo PNCF também passam a dispor de acesso ao PRONAF e demais programas destinados ao segmento da Agricultura Familiar (AF). Reconheça-se que a criação do Programa Nacional de Fortalecimento da Agricultura Familiar (PRONAF) foi um momento marcante para o segmento da AF, pois significou o reconhecimento do Estado para uma categoria historicamente negligenciada. $\mathrm{O}$ estabelecimento de um Programa voltado exclusivamente para o segmento decorreu de inúmeras ações de grupos sociais organizados, destacando-se os movimentos empreendidos pelos Sindicatos de Trabalhadores Rurais de todo o país, liderados pela Confederação Nacional dos Trabalhadores Rurais Agricultores e Agricultoras Familiares (CONTAG) (SCHNEIDER; MATTEI; CAZELLA, 2004).

Apesar do tardio reconhecimento pelo Estado brasileiro da relevância da AF, deve-se considerar a instituição do PRONAF como um marco importante, tendo-se em conta, principalmente, a destinação de recursos para o financiamento exclusivo para os agricultores familiares, inaugurando-se o processo de valorização institucional de uma categoria relegada ao descaso estatal (SCHNEIDER; MATTEI; CAZELLA, 2004).

Também merecem referências a resiliência e a capacidade de adaptação da categoria, posto que a $\mathrm{AF}$, não somente sobreviveu sem o respaldo estatal, como progrediu em alguns nichos, consolidando-se como substancial fornecedor de alimentos e fibras.

Não obstante, deve-se evidenciar que o universo da AF se apresenta bastante heterogêneo, sendo marcante a existência de significativo contingente de agricultores familiares descapitalizados e pobres, especialmente, no Semiárido (BARRETO FILHO; OLIVEIRA, 2016).

Conforme Rodrigues et al (2017), o Rio Grande do Norte tinha assentamentos realizados em 128 municípios através do PNCF, marcando presença em 77\% dos municípios do estado, contando-se com 846 assentamentos e beneficiando $5.833 \mathrm{fa}$ mílias. Observando-se ainda que 484 assentamentos foram financiados pela linha Combate à Pobreza Rural (CPR) e 362 pela modalidade Consolidação da Agricultura Familiar (CAF), totalizando um montante de $\mathrm{R} \$ 147.291 .121,70$. Os recursos foram aplicados na aquisição de terras ( $\mathrm{R} \$ 76.093 .232,55)$, através da compra de 126.818,20 hectares e R $\$ 64.277 .948,29$ aplicados em investimentos comunitários e básicos 
(totalizando R $\$ 140.371 .180,84$ ), os recursos remanescentes, aproximadamente R\$ 7 milhões, foram dispendidos em outros custos operacionais (RODRIGUES et al, 2017).

Rodrigues et al (2017) observou a contratação de operações concentradas em 10 municípios, totalizando 331 assentamentos, apontando como causas prováveis a disponibilidade de terras e reservas hídricas em tais localidades como facilitadores para a realização das operações através do PNCF. A percepção defendida por Rodrigues et al (2017) sobre as causas da concentração de operações não se adequa ao padrão existente em Portalegre/RN, tendo-se em conta que a área do município se localiza numa serra, com preponderância de minifúndios e sem reservatórios hídricos significativos.

\section{Contribuições do PNCF: Estudo de caso nas comunidades rurais de Portalegre/RN}

Segundo os dados do IBGE (2010), o município de Portalegre/RN tem área territorial de $110,054 \mathrm{~km}^{2}$ com densidade demográfica de $66,51 \mathrm{hab} / \mathrm{km}^{2}$. A população de 7.320 habitantes, sendo que 3.843 residentes na zona urbana e 3.476 com residência na zona rural, apresentando uma divisão da população entre a zona urbana e rural muito similar.

Os dados preliminares do Censo Agropecuário (2017) apontaram que o município tinha 418 estabelecimentos agropecuários, com área total de 3.678,8 hectares, sendo 488 hectares destinadas para as lavouras permanentes, 426 hectares ocupadas por lavouras temporárias, 1.140 hectares para pastagens (naturais e plantadas), 58 hectares ocupadas por matas naturais e 1.157 hectares utilizadas em sistemas agroflorestais (IBGE, 2017).

A caracterização socioeconômica referente aos 418 estabelecimentos agropecuários visitados pelo IBGE (2017) é apresentada na Tabela 1. 
Tabela 1 - Caracterização socioeconômica dos estabelecimentos rurais em Portalegre/RN (2017) - Dados selecionados

\begin{tabular}{|c|c|c|}
\hline Indicador & Quantidade & Unidade \\
\hline Estabelecimentos agropecuários (total) & 418 & Estabelecimentos \\
\hline Condomínio, consórcio ou união de pessoas & 11 & Estabelecimentos \\
\hline Produtor individual & 407 & Estabelecimentos \\
\hline Sexo do produtor $(\mathrm{M})$ & 358 & Estabelecimentos \\
\hline Sexo do produtor $(\mathrm{F})$ & 60 & Estabelecimentos \\
\hline Escolaridade do produtor - Nunca frequentou escola & 125 & Estabelecimentos \\
\hline Escolaridade do produtor - Classe de alfabetização & 136 & Estabelecimentos \\
\hline Escolaridade do produtor - Alfabetização de jovens e adultos & 5 & Estabelecimentos \\
\hline Escolaridade do produtor - Antigo primário & 34 & Estabelecimentos \\
\hline Escolaridade do produtor - Antigo ginasial & 6 & Estabelecimentos \\
\hline Escolaridade do produtor - Regular do ensino fundamental ou $1^{\circ}$ grau & 65 & Estabelecimentos \\
\hline Escolaridade do produtor - Técnico de ensino médio ou do $2^{\circ}$ grau & 8 & Estabelecimentos \\
\hline Escolaridade do produtor - Superior - graduação & 7 & Estabelecimentos \\
\hline Idade do produtor - menor que 30 anos & 14 & Estabelecimentos \\
\hline Idade do produtor - de 30 a menos de 60 anos & 218 & Estabelecimentos \\
\hline Idade do produtor - de 60 anos ou mais & 186 & Estabelecimentos \\
\hline
\end{tabular}

Fonte: IBGE (2017).

São predominantes: a propriedade individual dos estabelecimentos rurais, o analfabetismo e a baixa escolaridade dos produtores, a presença mais acentuada de homens como produtores e com idades mais avançadas. Menos de $2 \%$ dos estabelecimentos têm produtores com curso superior e pouco mais de $3 \%$ dos estabelecimentos têm produtores com menos de 30 anos, enquanto mais de $44 \%$ dos estabelecimentos têm produtores de 60 anos ou mais. Saliente-se que pouco mais de $14 \%$ dos estabelecimentos têm mulheres como responsáveis pela produção.

A Tabela 2 traz a caracterização produtiva dos estabelecimentos agropecuários identificados pelo IBGE (2017). 
Tabela 2 - Caracterização produtiva dos estabelecimentos rurais em Portalegre/RN (2017) Dados selecionados

\begin{tabular}{lcc}
\hline Indicador & Quantidade & Unidade \\
\hline Assistência técnica - recebe & 49 & Estabelecimentos \\
\hline Assistência técnica - não recebe & 369 & Estabelecimentos \\
\hline Utiliza adubação química e orgânica & 1 & Estabelecimentos \\
\hline Utiliza adubação orgânica & 31 & Estabelecimentos \\
\hline Não utiliza adubação & 386 & Estabelecimentos \\
\hline Utiliza agrotóxicos & 125 & Estabelecimentos \\
\hline Não utiliza agrotóxicos & 245 & Estabelecimentos \\
\hline Obteve financiamento/empréstimo & 92 & Estabelecimentos \\
\hline Não obteve financiamento/empréstimo & 326 & Estabelecimentos \\
\hline Preparo do solo - cultivo convencional & 116 & Estabelecimentos \\
\hline Preparo do solo - cultivo mínimo & 86 & Estabelecimentos \\
\hline Preparo do solo - direto na palha & 1 & Estabelecimentos \\
\hline Uso de tratores & 2 & Estabelecimentos \\
\hline Pessoal ocupado com laços de parentesco com o produtos & 418 & Estabelecimentos \\
\hline Pessoal ocupado sem laços de parentesco com o produtos & 37 & Estabelecimentos \\
\hline
\end{tabular}

Fonte: IBGE (2017).

A assistência técnica atende pouco mais de $10 \%$ dos produtores, evidenciando que o serviço tem deixado bastante a desejar, sendo provável que muitos produtores estejam fazendo uso equivocadamente de agrotóxicos e/ou deixando de utilizar os restolhos das atividades agropecuárias na adubação. Dos produtores que relataram a obtenção de financiamento/empréstimo, 52 informaram que a fonte foi o PRONAF, sugerindo que existe desconhecimento e/ou dificuldades dos produtores para acessarem os recursos do Programa.

Em relação ao preparo do solo, verifica-se que quase $28 \%$ praticam um cultivo convencional (limpam o terreno e plantam), cerca de $20 \%$ realizam um cultivo mínimo, consistindo em alguma ação de preparo da terra, como, por exemplo, recorrer a adubação.

Os dados indicam que os produtores agropecuários de Portalegre/RN estão realizando as atividades produtivas com reduzidas possibilidades de obterem ganhos de produtividade, ademais, como se constata pela exígua utilização de tratores (apenas dois estabelecimentos), aspectos que também sugerem maiores esforços, inclusive físicos, por parte dos produtores e suas famílias. Aliás, 100\% dos estabelecimentos têm pessoas ocupadas (724 pessoas) com algum parentesco em relação ao produtor 
e quase $10 \%$ dos estabelecimentos também recorrem ao trabalho de pessoas (71 pessoas) sem laços de parentesco com o produtor (IBGE, 2017).

A Tabela 3 se refere as atividades agropecuárias com maiores representatividades, em quantidades produzidas e tamanhos dos rebanhos.

Tabela 3 - Atividades agropecuárias com maior representatividade nos estabelecimentos rurais em Portalegre/RN (2017) - Dados selecionados

\begin{tabular}{lcl}
\hline Produto & Quantidade & Unidade \\
\hline Castanha de caju & 27 & Toneladas \\
\hline Fruto do caju & 165 & Toneladas \\
\hline Feijão & 79 & Toneladas \\
\hline Mandioca & 39 & Toneladas \\
\hline Milho & 100 & Toneladas \\
\hline Bovinos & 1.301 & Cabeças \\
\hline Caprinos & 1.482 & Cabeças \\
\hline Galináceos & 8.048 & Cabeças \\
\hline Ovinos & 635 & Cabeças \\
\hline Suínos & 740 & Cabeças \\
\hline
\end{tabular}

Fonte: IBGE (2017).

Os dados da Tabela 3 sugerem que os efeitos da seca prolongada (2012-2017) impactaram muito negativamente a atividade agropecuária existente no município, tendo-se em conta que em anos com chuvas mais regulares a produção agropecuária era bem mais satisfatória, conforme se depreende a partir dos dados dos anos de 2008 e 2010.

Tabela 4 - Produção agropecuária nos estabelecimentos rurais em Portalegre/RN - Comparativo (2008-2010) - Dados selecionados

\begin{tabular}{lccl}
\hline \multirow{2}{*}{ Produto } & \multicolumn{2}{c}{ Quantidade } & \multirow{2}{*}{ Unidade } \\
\cline { 2 - 3 } & $\mathbf{2 0 0 8}$ & $\mathbf{2 0 1 0}$ & \\
\hline Castanha de caju & 976 & 264 & Toneladas \\
\hline Mandioca & 320 & 480 & Toneladas \\
\hline Feijão & 200 & - & Toneladas \\
\hline Milho & 750 & - & Toneladas \\
\hline Bovinos & 2.344 & 2.065 & Cabeças \\
\hline Suínos & 1.822 & 1.742 & Cabeças \\
\hline Ovinos & 1.046 & 1.029 & Cabeças \\
\hline
\end{tabular}

Fonte: IBGE (2010) apud BARRETO FILHO (2017). 
Destaque-se a redução muito representativa da atividade da cajucultura, que, ao longo de muito tempo, constituiu-se na principalmente atividade desenvolvida nos estabelecimentos rurais de Portalegre/RN. Além, evidentemente, da queda da produção de mandioca e a redução dos rebanhos, especialmente, o de bovinos.

Portalegre/RN contava, na época da pesquisa de campo, com cinco assentamentos de crédito fundiário. Sendo que uma família foi contemplada através da linha de financiamento CAF e trinta e duas famílias beneficiárias através da linha CPR.

A implantação dos assentamentos de crédito fundiário no município de Portalegre/RN obedeceu aos critérios estabelecidos pelo PNCF para as desapropriações das terras. Verificando-se os requisitos burocráticos, como a documentação atualizada de proprietários e beneficiários, cadastramento de potenciais contemplados, liberação do crédito e nas transferências do imóveis para os beneficiários.

Contudo, no levantamento de campo, verificou-se que, do total de 33 famílias que estavam cadastradas e contempladas com os recursos do PNCF, apurou-se que apenas 20 famílias inicialmente beneficiadas pelo programa continuavam residindo nos assentamentos, bem como, seis famílias que não constavam como beneficiárias diretas do PNCF, mas que tinham passado a residir nas áreas dos assentamentos.

Dos cinco assentamentos, apurou-se que três deles já tinham quitado os financiamentos obtidos. Vale salientar que, conforme relatado pelos agricultores familiares, foi possível a quitação dos financiamentos através de uma bonificação de $95 \%$ de desconto nas dívidas que tinham com o Banco do Nordeste.

Em relação a localização dos assentamentos, observou-se que os deslocamentos do centro da cidade até as áreas foi de, aproximadamente, seis quilômetros para o mais próximo e 12 quilômetros para o mais distante. Os acessos para os assentamentos ocorrem em estradas sem pavimentação, sendo apontados por alguns moradores que, nos períodos chuvosos, são comuns a existência de pontos quase intransitáveis.

Saliente-se que o município de Portalegre/RN foi contemplado com o recebimento de máquinas através do Programa de Aceleração do Crescimento (PAC) - Máquinas e Equipamentos que, dentre outros objetivos, aponta a conservação das estradas vicinais como indispensável para o escoamento da produção agropecuária.

Com referência as práticas produtivas adotadas pelos agricultores familiares nos assentamentos, observou-se que a maior parte trabalha na agricultura de forma tradicional, praticamente sem recorrer a quaisquer recursos técnicos. Realizando-se as atividades com uso de enxada, queimadas e do arado com tração animal, com predominância para os cultivos de milho e do feijão (Figura 1 e Figura 2).

A falta de equipamentos e implementos requerem grande esforço físico dos agricultores familiares, também comprometem a capacidade laborativa e a saúde dos 
trabalhadores a ausência de Equipamentos de Proteção Individual. Em função das condições insatisfatórias para a exploração foram identificadas na pesquisa de campo pessoas recebendo auxílio da Previdência Social em decorrência de estarem incapacitados para o trabalho.

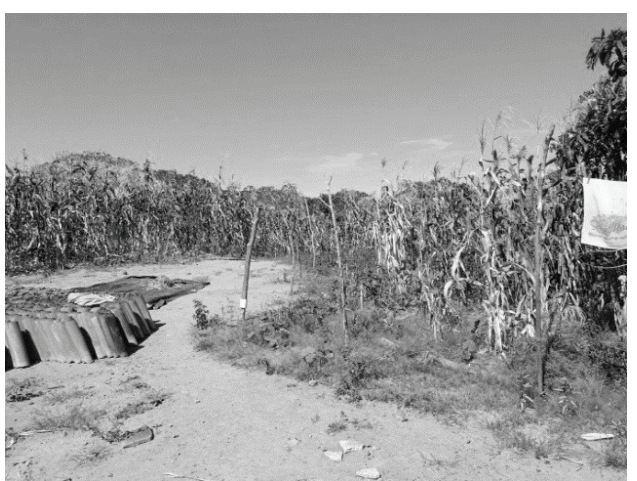

Figura 1 - Cultivo de milho e feijão.

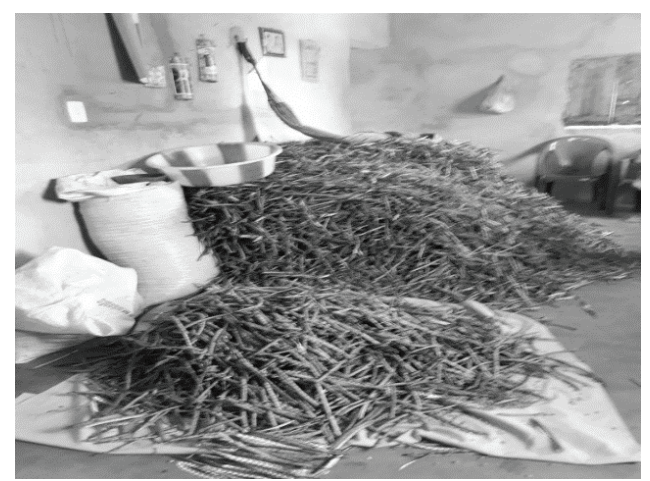

Figura 2 - Estocagem de feijão na palha.

Fonte: Acervo dos autores (2018).

Saliente-se também que o uso recorrente de queimadas, como técnica de preparação da terra para o cultivo, comprometem a qualidade dos solos em virtude da eliminação de material orgânico e tornam as áreas mais vulneráveis a ação das chuvas, contribuindo para o avanço da erosão.

A maior parte da produção de sequeiro serve para o autoconsumo familiar, sendo destinados para comercialização os excedentes obtidos nos anos em que as colheitas são mais satisfatórias.

Também se obtém renda através da comercialização de produtos de origem animal, como criações de galináceos, bovinos, suínos e caprinos e, rendas não agrícolas, pelo recebimento de benefícios sociais, com destaque para o Programa Bolsa Família.

Ademais, alguns dos assentados, para conseguirem completar a renda familiar ou para melhorar a condição de vida, afirmaram que exerceram outras atividades não agrícolas fora dos assentamentos, como: realização de trabalho temporário na construção civil, em empresas e até como motorista.

Observou-se que não existem ações coletivas em prol das comunidades assentadas, nem muita interação e/ou cooperação entre as famílias para a realização das atividades produtivas. Quase sempre, trabalham de forma individualizada e não demonstram laços de confiança que possam sinalizar para o estabelecimento de ações associativas. 
Apurou-se que a criação das associações não foi capaz de modificar o comportamento dos agricultores, apenas servindo para o cumprimento de exigências burocráticas para a participação em algum programa governamental, a exemplo do Programa RN Sustentável implementado pelo governo estadual através de empréstimo concedido pelo Banco Mundial e, principalmente, para acessar os recursos do PNCF.

As dificuldades financeiras apontadas pelos assentados estão diretamente relacionadas a pouca produção agropecuária, piorando-se o quadro com a estiagem prolongada (2012-2017). Segundo foi apurado junto as famílias que permaneceram nos assentamentos, a escassez hídrica proveniente do longo período de estiagem foi o principal motivo para que alguns beneficiários se deslocassem para a zona urbana e abandonassem as terras, ainda que, possivelmente, de forma provisória.

Ressalte-se que todas as residências dos assentados visitados tinham cisternas (Figura 3), mas mesmo assim a água armazenada durante o período das chuvas não foi suficiente para atender as necessidades das famílias ao longo do restante do ano. Conforme salientado por alguns assentados foi necessário comprar água de vendedores privados, com comprometimento da minguada renda familiar, entretanto a maioria dos assentados informou que foi possível esperar pelo abastecimento realizado pelo Exército Brasileiro para suprimento das necessidades básicas das famílias e para saciar a sede dos animais.
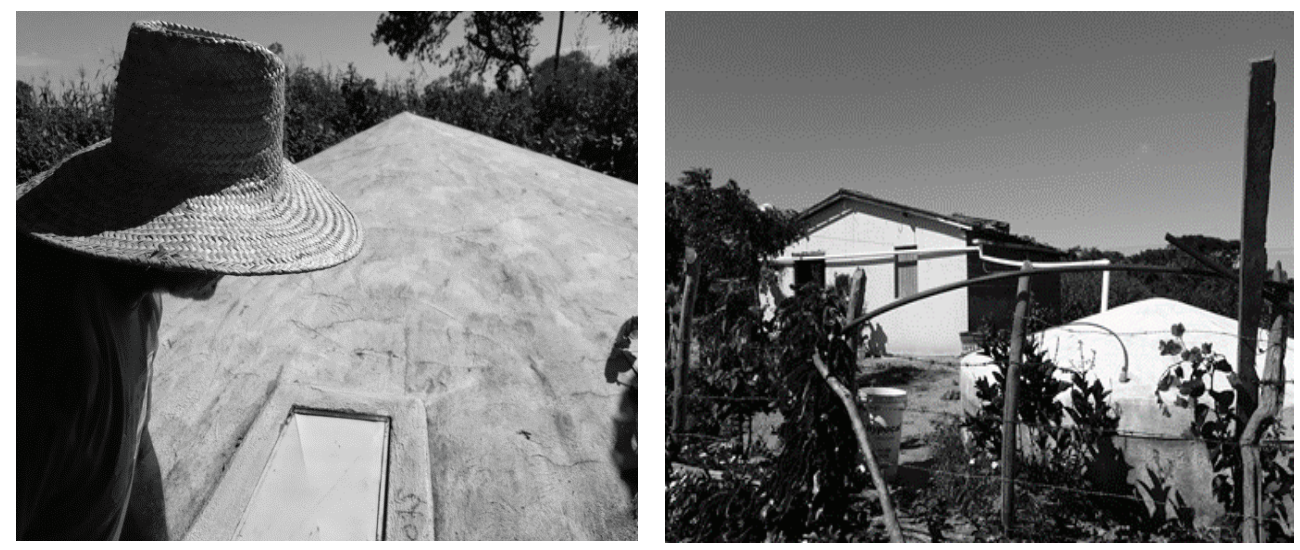

Figura 3 - Cisternas de placas.

Fonte: Acervo dos autores (2018).

A pesquisa apontou a existência de algumas particularidades, como o tamanho bem distinto das famílias (de dois membros até dez pessoas), mas, em linhas gerais, verificou-se certa semelhança em muitos aspectos socioeconômicos. 
Com relação ao grau de escolaridade observou-se que a maioria dos beneficiários tem apenas o ensino fundamental incompleto (78\% dos entrevistados), 52\% são beneficiários do Programa Bolsa Família, também foram identificados beneficiários de Benefício de Prestação Continuada (duas pessoas) e apenas uma família cadastrada no Programa de Aquisição de Alimentos.

O Assentamento Catolé, financiado através da linha de Consolidação da Agricultura Familiar, não tem mais residentes. Embora a família titular ainda esteja explorando o estabelecimento rural passou a residir na cidade de Portalegre/RN em decorrência das dificuldades com a escassez hídrica. Ademais, o titular do financiamento informou que já quitou a dívida e que a idade de 68 anos também contribuiu para a decisão de residir na zona urbana. Por tais circunstâncias não estavam sendo criados animais na área e as atividades de lavouras temporárias citadas foram: cultivos de milho e feijão (majoritariamente), plantios de fava e de arroz, predominando como lavoura permanente a exploração de cajueiros.

Os demais assentados pesquisados (quatro assentamentos) informaram que obtiveram os recursos através da linha de Combate à Pobreza Rural. Em todos os assentamentos foram mencionados, e identificados através da pesquisa de campo, a criação de galinhas, suínos, caprinos e bovinos. Embora o número de bovinos não seja muito significativo, verificou-se que estavam presentes em praticamente metade dos estabelecimentos rurais, significando que, mesmo num cenário de escassez hídri$\mathrm{ca}$, os assentados estavam conseguindo manter os animais vivos.

Em todas as áreas de assentamento foram mencionados os cultivos de milho e feijão (presentes em todos os assentamentos pesquisados) como lavouras temporárias mais importantes. Também foram apontadas plantações de arroz (dois assentamentos), mandioca (quatro assentamentos), fava (três assentamentos), batata doce (dois assentamentos), sorgo (dois assentamentos), além da presença de pastagens naturais em todos os estabelecimentos rurais ${ }^{1}$. Destacando-se também a presença de plantações de cajueiros nos cinco assentamentos como lavoura permanente mais representativa.

Com relação ao acesso de recursos do PRONAF, observou-se que as famílias assentadas e contempladas consideraram os recursos obtidos como sendo de grande importância para a melhoria na infraestrutura dos estabelecimentos rurais (na construção de pequenos armazéns e cercas) e para aquisição de animais (bovinos, caprinos, suínos e até galinhas). Foi possível identificar alguns poucos indícios de desvios de finalidade em relação as destinações para as quais os recursos do PRONAF teriam sido utilizados, como aquisições de bens para as residências, realização de melhorias nos imóveis, dentre outros. 
De acordo com Barreto Filho et al (2016, p. 9):

Existem oportunidades e perspectivas para assegurar aos agricultores familiares melhores condições para ampliação da produção, da produtividade e para gerar renda. Não basta a transferência de recursos através do PRONAF, embora se reconheça a importância do crédito, pois os agricultores familiares deixados a própria sorte não conseguem superar os obstáculos.

Em sintonia com a argumentação dos autores, verificou-se que a falta de assistência técnica nos últimos três anos preocupou bastante os agricultores familiares assentados. É provável que a falta de acompanhamento e assistência técnica sejam elementos explicativos para as eventuais inadequações no uso dos recursos. Ademais, a ausência do serviço de acompanhamento limita as possibilidades para os assentados utilizarem técnicas mais eficazes para aprimoramento das atividades produtivas, consequentemente, limitando a geração de renda proveniente da exploração dos lotes.

Também sinalizaram preocupações com relação aos pagamentos ainda não realizados, principalmente, apontando a redução das atividades produtivas em decorrência da longa estiagem (2012-2017) como a causa provável para eventuais atrasos.

Em decorrência das dificuldades provenientes da irregularidade pluviométrica não foi possível aferir, adequadamente, a geração de rendas das atividades produtivas. Em virtude de tal circunstância, optou-se por observar a diversificação produtiva como um elemento muito importante para sugerir que, em anos com chuvas mais regulares, é provável que as áreas dos estabelecimentos rurais sejam suficientes para geração de rendas capazes de suportar o pagamento do financiamento. Corrobora para tal impressão a presença de animais de porte em praticamente todos os estabelecimentos rurais, exceto em um, isso porque, acaso não fossem terras com bom potencial não faria sentido a manutenção, sobretudo de bovinos, em tais áreas.

A diversificação produtiva também sugere que os assentados que permaneceram nos lotes estão atentos, mesmo sem contar com assistência técnica, para a importância de reduzir os riscos associados a produção de poucos itens.

Ademais, verificou-se que as rendas não agrícolas auferidas, com regularidade, por parte das famílias assentadas não são muito representativas, quase sempre, provenientes do Programa Bolsa Família e que, portanto, não podem se constituir como fontes possíveis de recursos para o pagamento das obrigações assumidas.

Os assentados relataram dificuldades para obtenção dos recursos e excesso de burocracia como os principais problemas observados na execução do PNCF, mas em linhas gerais, fizeram avaliações positivas sobre o Programa, destacando-o como instrumento indispensável para que se tornassem proprietários de terras. 
Instigados para se posicionarem sobre o Programa foram observadas as seguintes falas: Sair da condição de parceiros ou de trabalhadores rurais para a de dono da terra; não precisar mais pagar renda para produzir; possuir terra para trabalhar e; possuir casa própria.

\section{Conclusões}

O problema da concentração fundiária no Brasil se estende por várias décadas, e é mais intenso nas regiões mais pobres do país, como Norte e Nordeste. Fato que tem gerado desigualdades sociais, desemprego, concentração de renda e pobreza.

A agricultura familiar pela sua importância econômica, social e ambiental precisa ser vista como uma categoria imprescindível ao desenvolvimento rural. Para tanto, faz-se necessário o Poder Público ser capaz de articular os diversos programas existentes para assim potenciar a atividade.

Muito mais do que a necessidade de executar novas ações, verificou-se na pesquisa realizada que se faz indispensável maior capacidade de articulação das ações existentes. No caso dos cinco assentamentos, observou-se o atendimento da demanda primária em relação ao acesso à terra própria através do PNCF, também amplo atendimento pelo Programa Bolsa Família, mas não se verificou nenhum tipo de sinergia entre os programas.

Em decorrência da fragilidade socioeconômica reconhecidamente mais acentuada entre famílias de assentados seria desejável que o PBF fosse capaz de oferecer um adicional monetário para tal público, com o estabelecimento de uma condicionalidade específica associada a permanência nos lotes por parte das famílias e/ ou frequência em cursos de Educação de Jovens e Adultos para promover a melhoria do nível de escolaridade dos assentados.

Na mesma linha de articulação de ações seria desejável que todas as famílias assentadas recebessem orientações para obtenção de recursos através do PRONAF, salientando-se o necessário ativismo das secretarias municipais de agricultura, a partir de ações realizadas através de Agentes de Desenvolvimento para consecução de tal propósito. Ademais, seria necessário que todos os agricultores assentados também recebessem ajuda para enquadramento como fornecedores do Programa de Aquisição de Alimentos.

Não menos importante é a garantia de assistência técnica, pois as técnicas rudimentares utilizadas são determinantes para a baixa produtividade, bem como 
para a exaustão precoce dos solos e a provável inviabilização das atividades agropecuárias. Ademais, a assistência técnica deve desempenhar papel relevante para que os assentados sejam estimulados a manterem a diversificação produtiva e para a utilização dos recursos disponíveis nos estabelecimentos rurais, com o objetivo de otimizar as sinergias entre as diversas atividades produtivas e, consequentemente, reduzir as aquisições de produtos externos.

Por fim, seria desejável que a questão agrária fosse firmemente enfrentada a partir da vontade soberana da sociedade brasileira, contudo, tem-se que reconhecer a efetividade da ação organizada para a defesa da propriedade latifundiária, inclusive a improdutiva, por parte da elite econômica nacional. Mesmo quem não tem terra se perfila na defesa dos latifúndios e o verdadeiro conluio das forças econômicas dominantes e, majoritariamente, conservadoras continuam bloqueando ações dignas de uma verdadeira Reforma Agrária.

Conforme já pontuado anteriormente, também foram observados pontos críticos em relação as situações vivenciadas pelos agricultores assentados em Portalegre/RN, tais como: ausência de assistência técnica, dificuldades de acesso às áreas em alguns períodos do ano em virtude de falta de manutenção das estradas vicinais, preocupações em relação a possíveis inadimplemento das prestações, abandono dos lotes por parte de algumas famílias e a presença de famílias não contempladas pelo PNCF em alguns assentamentos.

Verifica-se que a atual coalizão que comanda o país se posiciona abertamente em defesa dos interesses do agribusiness, ignorando quaisquer ações que visem à desconcentração de terra e a inclusão do homem do campo, de tal forma que aumente seu nível de renda e melhore suas condições de vida. Portanto, as iniciativas que tinham como propósito melhorar as condições de vida dos agricultores sem terra ou com pouca terra, como o PNCF estão sob fogo cerrado.

\section{Nota}

${ }^{1}$ Nos cinco assentamentos (Catolé, São Francisco, São Miguel, Serrinha e Terra Boa) foram identificados 33 estabelecimentos rurais de beneficiários diretamente contemplados através do PNCF. Contudo durante as visitas realizadas foram localizadas famílias residentes que não tinham participado dos processos de assentamento, sugerindo a possibilidade de desvirtuamento do propósito do Programa. 


\section{Referencias}

BARRETO FILHO, Boanerges de Freitas; ESTEVAM, Stênio Maia; SILVA, Alcimária Fernandes da. Agricultura familiar - estudo de caso no Assentamento São Benedito em Portalegre/RN. E-book do $1^{\circ}$ Encontro Nacional de Planejamento Urbano e Regional no Semiárido: I ENAPUR-Semiárido [recurso eletrônico] / Organização Larissa da Silva Ferreira Alves, Joseney Rodrigues de Queiroz Dantas, Alcides Leão Santos Júnior. - Dados eletrônicos. - Natal: CCHLA, 2016. Disponível em: <https:// drive.google.com/file/d/0B2XGuqMcKRTudTBYYUl5aUx4WkU/view>. Acesso em: 20 ago. 2018.

BARRETO FILHO, Boanerges de Freitas; OLIVEIRA, Maria Kalina de Souza. O PRONAF na Comunidade Quilombola "Negros Felicianos do Alto” de Portalegre/ RN. XI SOBER NORDESTE. 2016. Anais. Disponível em: <http://sobernordeste2016.com.br/anais.php>. Acesso em: 16 mar. 2019.

BARRETO FILHO, Boanerges de Freitas. O cooperativismo/associativismo em Portalegre/RN: resultados e desafios. 1º. ERESPP-Semiárido. Anais. 2017. Disponível em: <http://www.editorarealize.com.br/revistas/erespp/anais.php>. Acesso em: 16 mar. 2019.

GALINDO, Ernesto et al. Programa Nacional de Crédito Fundiário (PNCF): uma avaliação de seus impactos regionais. Texto para Discussão, Instituto de Pesquisa Econômica Aplicada (IPEA), 2015. Disponível em: <https://www.econstor.eu/bitstream/10419/121707/1/819705497.pdf>. Acesso em: 16 mar. 2019.

INSTITUTO NACIONAL DE COLONIZAÇÃO E REFORMA AGRÁRIA (INCRA). Reforma agrária. 2011. Disponível em: <http://www.incra.gov.br/reforma-agraria > Acesso em: 05 out. 2017.

INSTITUTO BRASILEIRO DE GEOGRAFIA E ESTATÍSTICA (IBGE). Cidades Portalegre/RN. 2010. Disponível em: <https://cidades.ibge.gov.br/brasil/rn/portalegre/panorama>. Acesso em: 25 mar. 2019.

INSTITUTO BRASILEIRO DE GEOGRAFIA E ESTATÍSTICA (IBGE). Censo Agropecuário - Resultados preliminares. 2017. Disponível em: <https://cidades. ibge.gov.br/brasil/rn/portalegre/pesquisa/24/76693>. Acesso em: 29 mar. 2019. 
MARTINE, George. A trajetória da modernização agrícola: a quem beneficia?. Lua Nova: Revista de Cultura e Política, n. 23, p. 7-37, 1991. Disponível em: <http:// www.scielo.br/scielo.php?pid=S0102-64451991000100003\&script $=$ sci_arttext $>$. Acesso em: 20 maio 2018.

MINISTÉRIO DO DESENVOLVIMENTO AGRÁRIO (MDA). Programa Nacional de Crédito Fundiário: para quem é da terra criar raízes. Brasília: MDA, 2006. Disponível em: <https://slideplayer.com.br/slide/385483/>. Acesso em: 20 maio 2018.

RODRIGUES, Paula Valeria Ferreira de Almeida; RAMOS, Nerize Laurentino; ARAUJO, Maria Eduarda Dias de. Mapeamento do Programa Nacional de Crédito Fundiário (PNCF) no Estado Rio Grande do Norte. I CONIDIS. Anais. 2017. Disponível em: $<$ http://www.editorarealize.com.br/revistas/conidis/anais.php $>$. Acesso em: 22 maio 2018.

SANTOS, Patrícia Eveline dos; SILVA NETO, Benedito. O PROGRAMA NACIONAL DE CRÉDITO FUNDIÁRIO NO PROCESSO DE DESENVOLVIMENTO-UMA ANÁLISE A PARTIR DA DINÂMICA DA AGRICULTURA DE INHACORÁ-RS. 2011. Disponível em: <http://www.fahor.com.br/publicacoes/jopec/2011/ Artigos/O_PROGRAMA_NACIONAL_DE_CREDITO_FUNDIARIO_NO_PROCESSO_DE_DESENVOLVIMENTO_.pdf $>$. Acesso em: 5 out. 2018.

SCHNEIDER, Sérgio; MATTEI, Lauro; CAZELLA, Ademir. Histórico, caracterização e dinâmica recente do PRONAF. SCHNEIDER, Sérgio et. al, 2004. Disponível em: <https://s3.amazonaws.com/academia.edu.documents/43198705/2004_-_Cap_ Historico_Pronaf_Sergio_Lauro_Ademir_Livro_PP_e_Participa.pdf?AWSAccess KeyId=AKIAIWOWYYGZ2Y53UL3A\&Expires $=1553836810 \&$ Signature $=$ ubkjic 9 WtDl0uiIJvloSq\%2BQguCY\%3D\&response-content-disposition=inline\%3B\%20filename\%3DHistorico_caracterizacao_e_dinamica_rece.pdf $>$. Acesso em: 5 out. 2018. 